\title{
Hyaluronic acid content of deep and subcutaneous bursae of man
}

\author{
JUAN J. CANOSO, MICHAEL T. STACK, AND KENNETH D. BRANDT \\ From the Rheumatology Section, Boston Veterans Administration Medical Center, and the Multipurpose \\ Arthritis Centers of Boston University, Boston MA, and Indiana University, Indianapolis IN, USA
}

SUMMARY To provide a comparison of the contents of subcutaneous and deep bursae we dissected these structures from unfixed cadavers without apparent joint disease. No free fluid was found within any olecranon or prepatellar bursae (examples of subcutaneous bursae), while viscous fluid was invariably present in the (deep) retrocalcaneal bursae. The hyaluronic acid content of the washings of 5 rectrocalcaneal bursae ranged from 142 to $591 \mathrm{nmol}$ hexosamine (mean $=281 \mathrm{nmol}$ hexosamine). In contrast, the hyaluronic acid content of 4 olecranon bursae was much lower (range 35-72 nmol, mean 53 nmol hexosamine), and hyaluronate was not detected in washings from either of 2 prepatellar bursae. The greater hyaluronate content of the retrocalcaneal bursae did not appear to be due to a greater surface area, since on the basis of calculations made from plaster casts the surface areas of the olecranon and prepatellar bursae were approximately 3 times and 2 times, respectively, greater than that of the retrocalcaneal bursae. The data suggest that, although hyaluronic acid may lubricate deep bursae, other factors may be more important in reducing friction within superficial bursae.

Bursae are closed sacs which are present in sites where tendons rub over bones, ligaments, or other tendons, or where skin moves over bony prominences. It is generally agreed that the main function of bursae is to facilitate the play of one structure upon another. Bursal lubrication is therefore central to normal bursal function. Although bursae have been the subject of detailed anatomical studies, ${ }^{12}$ and analyses of the contents of bursal fluid from patients with a variety of rheumatic diseases have been reported, ${ }^{34}$ information is lacking on the composition of normal human bursal fluid..$^{5}$ In the present study we dissected subcutaneous and deep bursae of unfixed cadavers, evaluated the bursal fluid macroscopically, and measured the amount of hyaluronic acid in bursal washings.

\section{Materials and methods}

Macroscopic studies. Two subcutaneous bursae (olecranon and prepatellar) and one deep bursa (retrocalcaneal) were dissected on one or both sides in 10 adult male unfrozen cadavers which had previously been refrigerated for a maximum of $\mathbf{4 8}$ hours.

Accepted for publication 2 February 1982.

Correspondence to J. J. Canoso, MD, D10-93, Boston Veterans Administration Medical Center, 150 South Huntington Avenue, Boston MA 02130, USA.
In each case the bursal lining was observed and the presence of any bursal fluid was noted. The lining was then lightly touched with a finger, which was withdrawn to provide a string sign. ${ }^{6}$

Bursal washings. In 5 additional cadavers, which had been preserved as above, the bursae were punctured with a no. 19 butterfly needle and flushed with a syringe 5 times with $6 \mathrm{ml}$ portions of distilled water at room temperature, after which the bursal contents and washings were lyophilysed. The olecranon and prepatellar bursae were flushed through a single needle, while 2 needles were inserted into each retrocalcaneal bursa to allow flushing with 2 syringes. No leakage occurred during the washing procedure. After this procedure the position of the needle was ascertained by sharp dissection, and a sample of the bursal wall at a site some distance from the needle was obtained for routine histological study after staining with haematoxylin-eosin. None of the subjects whose bursae were employed for macroscopic studies or to obtain washings had a history of, or evidence of, joint disease on post-mortem examina-

\section{Results}

MACROSCOPIC APPEARANCE AND HISTOLOGY Olecranon and prepatellar bursae. No free fluid was 
tion, except for one case, patient 4 (Table 1), who 24 hours before death had had an attack of pseudogout in the right elbow and wrist, proved by demonstration in the joint fluid of crystals consistent with calcium pyrophosphate dihydrate by polarising microscopy. Only the left olecranon and right retrocalcaneal bursae of this individual were studied.

Mucin test. $0.25 \mathrm{ml}$ of sampled bursal washings was added to $2 \mathrm{ml}$ of $2 \%$ acetic acid. The solution was mixed gently with a stirring rod for a few seconds and was observed immediately for the presence of a precipitate (mucin). ${ }^{6}$

Measurement of hyaluronic acid. The lyophilysed bursal washings were dissolved in $10 \mathrm{mM}$ Tris- $\mathrm{HCl}$, pH 8.0, containing $0.001 \mathrm{M} \mathrm{CaCl}_{2}$ and digested with proteinase $\mathrm{K}$ (EC 3.4 .21 .14$)(0.5 \mathrm{mg}$ of enzyme $/ \mathrm{ml})$ at $60^{\circ} \mathrm{C}$ for $18 \mathrm{~h}$. After digestion the samples were concentrated by drying under a stream of air, and $0.25 \mu \mathrm{l}$ was applied to a cellulose acetate membrane and electrophoresed in cadmium acetate buffer. ${ }^{7}$ The strips were then immediately immersed in $1 \%(\mathrm{w} / \mathrm{v})$ alcian blue in $95 \%$ ethanol-0.05 $\mathrm{M}$ sodium acetate $(1: 1 \mathrm{v} / \mathrm{v})$, destained in $10 \%$ ethanol- $5 \%$ glacial acetic acid (v/v), and cleared in $40 \%(v / v)$ methyl-2pyrrolidine in water for 5 minutes. After mounting on microscope slides the strips were dried at $90^{\circ} \mathrm{C}$ for 20 minutes and the absorbance of each band was determined with a Zeiss PMQ II spectrophotometer with linear gel transport. The data were integrated with a Spectra Physics SP1000 computing integrator. Purified hyaluronic acid from umbilical cord and chondroitin sulphate (both from Sigma Chemical Co., St Louis, MO) and dermatan sulphate (Miles Research Products, Elkhart, IN) served as standards. All results were expressed as nmol of glycosaminoglycan hexosamine. The presence of hyaluronic acid was confirmed by incubating aliquots of the concentrated digests of bursal washings with $0.5 \mu \mathrm{l}$ of streptomyces hyaluronidase (EC 4.2.2.1) in $50 \mathrm{mM}$ sodium acetate, $\mathrm{pH} 5 \cdot 0$, at $60^{\circ} \mathrm{C}$ for $4 \mathrm{~h}$, following which the band on the electrophoretogram which corresponded to hyaluronic acid was no longer visible. Streptomyces hyaluronidase has been shown to be specific for hyaluronic acid. ${ }^{89}$ The assay method employed here has been found to be linear to $3 \mathrm{nmol}$ of glycosaminoglycan hexosamine, and sensitive to $0.05 \mathrm{nmol}$ of glycosaminoglycan hexosamine, per $0 \cdot 25 \mu$ l spot. ${ }^{9}$

Measurement of bursal surface area. Casts were obtained by low-pressure injection of several bursae with a $50 \%$ solution of plaster-of-Paris. ${ }^{10}$ After removal of the hardened casts pieces of graph paper, lined in millimeter squares, were cut and apposed to the casts to cover the entire surface, following which the squares were counted to provide a indication of bursal surface area. present in any of these bursae with the exception of the olecranon bursae in one patient who had died with anasarca. The string sign was negative in all cases.

Retrocalcaneal bursae. In each case a trace of highly viscous fluid was present and the bursal fluid string sign measured at least $4 \mathrm{~cm}$.

The histological appearance was normal in every case, and varied with the bursa studied and the topographical location within each bursa. A monolayer of flattened cells overlying dense connective tissue was typically present in the posterior (tendinous) portion of the retrocalcaneal bursa and in the roof of the olecranon bursa (Fig. 1). Folds and villi were common in the peripheral portions of the olecranon and prepatellar bursae where the sublining tissue was predominantly areolar (Fig. 2) and in the proximal portion of the retrocalcaneal bursa where the supporting tissue was regularly adipose. Blood vessels were most abundant in the areolar or fatty bursal

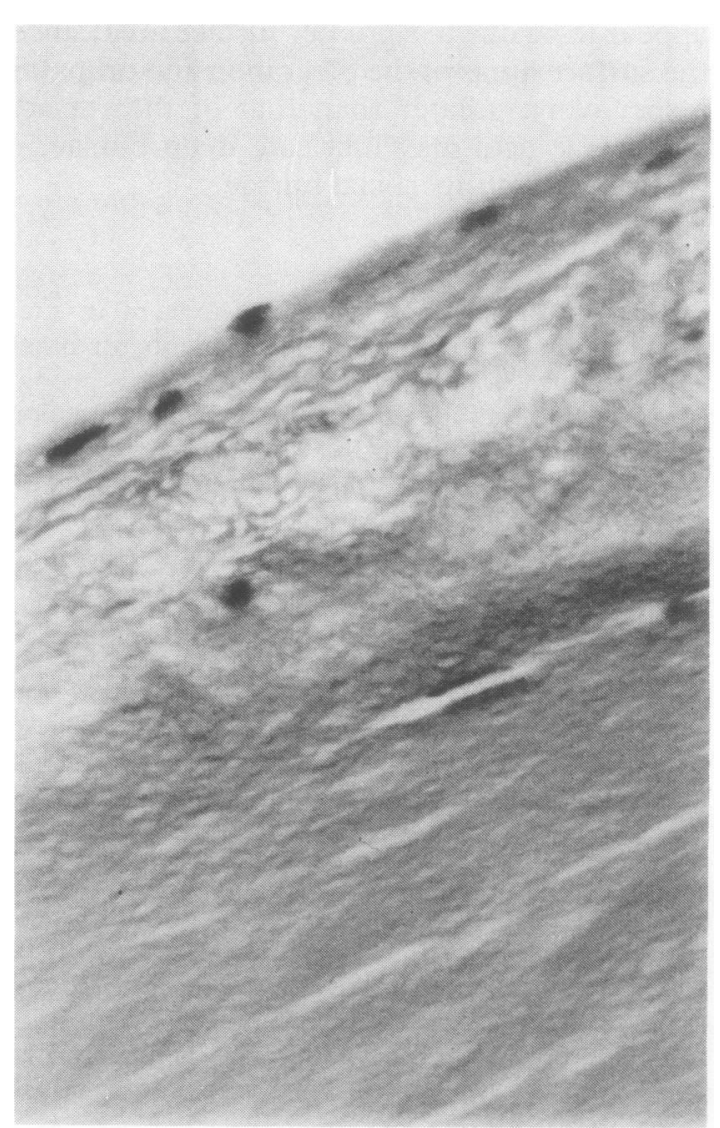

Fig. 1 Posterior (tendinous) portion of the retrocalcaneal bursa of subject 3 . The lining cells rest on the epitenon. Note the absence of inflammation. $(H \& E, \times 360)$. 


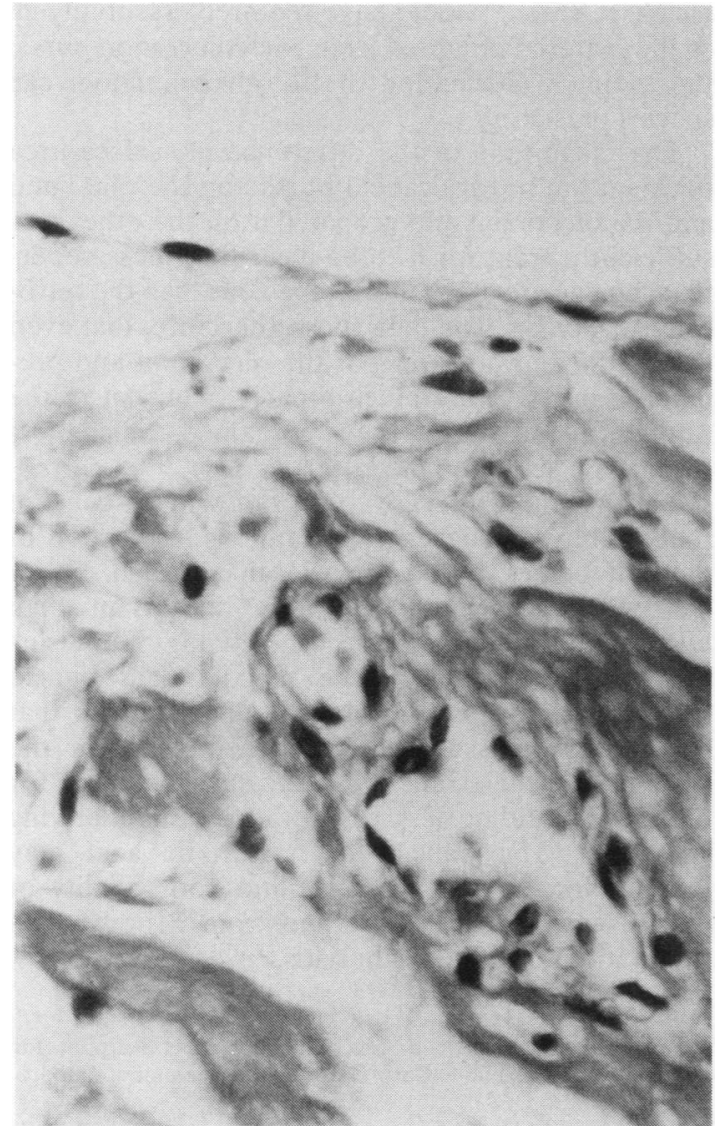

Fig. 2 Peripheral portion of the olecranon bursa of subject 3. The cellular lining is supported by areolar connective tissue. $(H \& E, \times 360)$. regions. No evidence of inflammation was present in any of the bursae examined.

\section{ANALYSES OF BURSAL WASHINGS}

A mucin precipitate formed after addition of dilute acetic acid to 3 of 4 retrocalcaneal bursal washings tested. In contrast, the material from the olecranon bursae did not yield a positive mucin test. Tests for mucin were not performed on either of the specimens for prepatellar bursae.

The hyaluronic acid content of the washings of 5 of the 6 retrocalcaneal bursa samples ranged from 142 to $591 \mathrm{nmol}$ hexosamine (Table 1). Material which stained with alcian blue was present also in the washings of the 6th retrocalcaneal bursa studied, but the identity of the glycosaminoglycans could not be resolved on the electrophoretogram. In contrast to the above, the hyaluronic acid content of the washings from the 4 olecranon bursae studied was considerably lower, and ranged from 35 to $72 \mathrm{nmol}$ of hexosamine, and no hyaluronate was detected in the samples from either of the prepatellar bursae examined. Hyaluronic acid was the only glycosaminoglycan detected in the bursal washings, except for one case (retrocalcaneal bursa washings of subject 5; Table 1), in which approximately $45 \mathrm{nmol}$ of glycosaminoglycan hexosamine which had the electrophoretic mobility of dermatan sulphate was also present.

\section{COMPARISONS OF BURSAL SURFACE AREA}

From the measurements of the plaster casts the surface area of 4 olecranon bursae was found to be approximately $20,30,36$, and $36 \mathrm{~cm}^{2}$, respectively (mean $=30.5 \mathrm{~cm}^{2}$ ), while 3 prepatellar bursae had surface areas of 19,20 , and $24 \mathrm{~cm}^{2}\left(\right.$ mean $\left.=21 \mathrm{~cm}^{2}\right)$.

Table 1 Analyses of bursal contents

\begin{tabular}{|c|c|c|c|c|c|c|c|}
\hline Subject & Age & Sex/race & Primary diagnosis & Rheumatic disease & Bursae examined & Mucin test & $\begin{array}{l}\text { Hyaluronic acid, } \\
\text { nmol hexosamine }\end{array}$ \\
\hline 1 & 77 & $\mathbf{M} / \mathbf{W}$ & $\begin{array}{l}\text { Pneumonia, upper } \\
\text { gastrointestinal bleeding }\end{array}$ & None & $\begin{array}{l}\text { L olecranon } \\
\mathbf{R} \text { retrocalcaneal } \\
\mathbf{L} \text { retrocalcaneal }\end{array}$ & $\begin{array}{l}\text { Negative } \\
\text { Positive } \\
\text { Positive }\end{array}$ & $\begin{array}{r}55 \\
154 \\
144\end{array}$ \\
\hline $\begin{array}{l}2 \\
3\end{array}$ & $\begin{array}{l}62 \\
66\end{array}$ & $\begin{array}{l}\mathbf{M} / \mathbf{W} \\
\mathbf{M} / \mathbf{W}\end{array}$ & $\begin{array}{l}\text { Oesophageal carcinoma } \\
\text { Cardiac failure }\end{array}$ & $\begin{array}{l}\text { None } \\
\text { None }\end{array}$ & $\begin{array}{l}\mathbf{R} \text { prepatellar } \\
\mathbf{L} \text { olecranon } \\
\mathbf{R} \text { retrocalcaneal }\end{array}$ & $\begin{array}{l}\text { ND } \\
\text { Negative } \\
\text { Positive }\end{array}$ & $\begin{array}{l}\text { N det. } \\
35 \\
591\end{array}$ \\
\hline 4 & 85 & $\mathbf{M} / \mathbf{W}$ & Pneumonia & $\begin{array}{l}\text { Pseudogout, } R \\
\text { elbow, and } R \text { wrist }\end{array}$ & $\begin{array}{l}\mathbf{L} \text { olecranon } \\
\mathbf{R} \text { retrocalcaneal }\end{array}$ & $\begin{array}{l}\text { Negative } \\
\text { Negative }\end{array}$ & $\begin{array}{r}72 \\
142\end{array}$ \\
\hline 5 & 67 & $\mathbf{M} / \mathbf{W}$ & $\begin{array}{l}\text { Pneumonia, pancreatic } \\
\text { carcinoma }\end{array}$ & None & $\begin{array}{l}\text { L olecranon } \\
\mathbf{R} \text { prepatellar } \\
\mathbf{R} \text { retrocalcaneal } \\
\mathbf{L} \text { retrocalcaneal }\end{array}$ & $\begin{array}{l}\text { ND } \\
\text { ND } \\
\text { ND } \\
\text { ND }\end{array}$ & $\begin{array}{l}50 \\
\text { N det. } \\
\text { - }^{*}\end{array}$ \\
\hline
\end{tabular}

ND $=$ Not done.

$\mathrm{N}$ det. $=$ not detected (sensitivity of method $\leqslant 10 \mathrm{nmol}$ of hyaluronate hexosamine).

*Type of glycosaminoglycan present was unresolved after deproteinisation.

†45 nmol hexosamine with the electrophoretic mobility of dermatan sulphate was also present. 
A single retrocalcaneal bursa was studied and had a surface area of approximately $8 \mathrm{~cm}^{2}$.

\section{Discussion}

In his classic treatise on bursae Monro stated in $1788^{1}$ that 'the inner side of the membrane of the bursa is not only smooth but, by the copious secretion of a lubricating liquor, is rendered extremely slippery.' He further described bursal fluid as having 'the same color, consistency and properties as that of the joint.' This view persists in some current textbooks of anatomy, ${ }^{11-13}$ while others describe differences between the contents of deep and subcutaneous bursae. ${ }^{14-16}$ Thus according to Testut and Latarjet ${ }^{14}$ deep bursae contain a small amount of unctuous and stringing fluid while subcutaneous bursae contain a transparent fluid analogous to lymph. In assessing Monro's findings it is important to note that his treatise deals only with deep bursae. His observations therefore should not be extrapolated to subcutaneous bursae.

The present study indicates that a fluid similar to joint fluid is indeed found in a normal deep bursa (retrocalcaneal), but not in either of 2 subcutaneous bursae (olecranon, prepatellar). It should be emphasised that the bursae which we chose for study never communicate with joints. In contrast, several other bursae (e.g., gastrocnemius-semimembranosus, iliopsoas, subacromial), especially in the elderly, often communicate with the neighbouring joint. ${ }^{17}$

Even though there was fluid in every retrocalcaneal bursa examined, it should be emphasised that they were histologically normal. With only a single exception none of the subjects from whom they were obtained had evidence of joint disease, and none had documented complaints referable to the ankle or foot. Furthermore, histological examination was normal in every case.

The relatively large amount of hyaluronic acid which we found in 5 of the 6 retrocalcaneal bursae correlates well with the demonstration of a mucin precipitate (Table 1) and the presence of a positive string test. In contrast the olecranon bursae, which contained much less hyaluronic acid, invariably gave a negative string test and their washings failed to give a positive mucin test. Analogously the string test was negative with the prepatellar bursae, in whose washings hyaluronate was not detected (see Table 1). Use of cellulose acetate electrophoresis and alcian blue staining to measure small quantities of glycosaminoglycan permitted determination of the species of glycosaminoglycan present on the basis of electrophoretic migration, with confirmation by specific enzyme digestion with hyaluronidase. In comparison, measurement of hyaluronate uronic acid by the car- bazole reaction ${ }^{18}$ would have required essentially all of the material obtained from each olecranon bursa, precluding confirmation of the glycosaminoglycan species present.

The magnitude of the difference in surface area between the retrocalcaneal bursae on the one hand and the olecranon and prepatellar on the other was sufficiently great for it to be clear that these superficial bursae are much more capacious than the retrocalcaneal bursa. The data show, therefore, that even though the surface areas of the olecranon and prepatellar bursae were much greater than that of the retrocalcaneal bursa they contained much less hyaluronic acid than the latter.

The present results are consistent with the concept that hyaluronic acid is important for lubrication of the soft tissues of the retrocalcaneal bursa. Other factors, however, may be more important than hyaluronic acid in facilitating the gliding of one surface over the other in the subcutaneous bursae studied herein. Dissection studies have shown that loose areolar tissue is constantly present in the periphery of these bursae, and this may account for much of the gliding of skin over the firmer underlying structures. The paucity of hyaluronic acid may account for the low viscosity and poor quality of mucin observed in bursal fluid from patients with traumatic subcutaneous bursitis. ${ }^{4}$

We are grateful to Gayle E. McGinnis and Chris Scarpone for technical assistance, and to Carol Barnstead for secretarial support.

This work was supported in part by grants from the National Institute of Arthritis, Metabolism, Digestive and Kidney Diseases AM 20613 and AM 20582, and a Clinical Research Center grant from the Arthritis Foundation. M.T.S. is a Research Fellow of the Arthritis Foundation.

\section{References}

1 Monro A. A Description of All the Bursae Mucosae of the Human Body. Edinburgh: Elliot, 1788: 23-5.

2 Schreger B G. De Bursis Mucosis Subcutaneis. Erlangen, 1825.

3 Ropes M W, Bauer W. Synovial Fluid Changes in Joint Disease. Cambridge: Harvard University Press, 1953: 120-1.

4 Canoso J J, Yood R A. Reaction of superficial bursae in response to specific disease stimuli. Arthritis Rheum 1979; 22: $1361-4$.

5 Bywaters E G L. Lesions of bursae, tendons and tendon sheaths. Clin Rheum Dis 1979; 5: 883-925.

6 Cohen A S, Brandt K D, Krey P R. Synovial fluid. In: Cohen A S, ed. Laboratory Diagnostic Procedures in the Rheumatic Diseases. 2nd ed. Boston: Little, Brown, 1975: 1-62.

7 Curwen F D, Smith S C. Quantitative microanalysis of aortic glycosaminoglycans. Anal Biochem 1977; 79: 291-301.

8 Jourdian G W, Wolfman M, Sarber R, Disiler J. A specific, sensitive method for the determination of hyaluronate. Anal Biochem 1979; 96: 474-80.

9 Stack M T, Golichowski A G. Determination of glycosaminoglycan concentration and specific activity by solid phase spectrophotometry and fluorography. Electrophoresis in press. 
10 Lindgren P G. Gastrocnemio-semimembranosus bursa and its relation to the knee joint. II. Post mortem radiography. Acta Radiol (Diagn) (Stockh) 1977; 18: 698-704.

11 Stockwell R A. Joints. In: Romanes G J, ed. Cunningham's Textbook of Anatomy. 12th ed. Oxford: Oxford University Press, 1981: 218.

12 Snell R S. Clinical Anatomy for Medical Students. 2nd ed. Boston: Little, Brown, 1981: 17.

13 Basmajian J V. Grant's Method of Anatomy. 10th ed. Baltimore: Williams and Wilkins, 1980: 22.
14 Testut L, Latarjet A. Traité d'anatomie humaine. 9th ed. Paris: Doin, 1949: 3: 472, 762.

15 Cummins H. The skin and breasts. In: Anson B J, ed. Morris' Human Anatomy. 12th ed. New York: McGraw-Hill, 1966: 118.

16 Warwick R, Williams P L. Gray's Anatomy. 36th ed. Philadelphia: Saunders, 1980: 522 .

17 Canoso J J. Bursae, tendons and ligaments. Clin Rheum Dis. 1981; 7: 189-221.

18 Bitter T, Muir H M. A modified uronic acid carbazole reaction. Anal Biochem 1962; 4: 330-4. 